\title{
Effectiveness of Prophylactic Cervical Cerclage in Prolonging Higher-Order Multiple Pregnancies
}

"Nail Obeidat, ${ }^{1}$ Haifa Alchalabi, ${ }^{1}$ Maha Obeidat, ${ }^{2}$ Bahauddin Sallout, ${ }^{3}$ Shereen Hamadneh, Jehan Hamadneh, ${ }^{1}$ Yousef Khader, ${ }^{5}$ Zouhair Amarin ${ }^{1}$

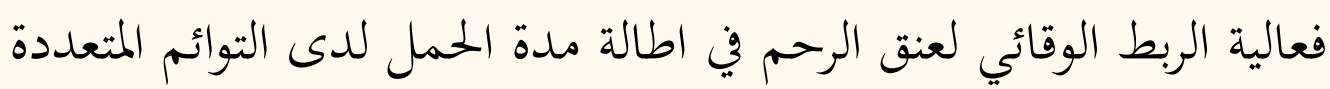

نائل عبيدات، هيفا الجلبي، هها عبيدات، بهاء الدين سلوت، شيرين حمادنة، جيهان حمادنة، يوسف خضر، زهير أمارين

ABSTRACT: Objectives: This study aimed to assess the value of prophylactic cervical cerclage in prolonging higherorder multiple pregnancies. Methods: This retrospective study included all women with higher-order multiple pregnancies beyond 24 gestational weeks treated at the King Abdullah University Hospital in Irbid, Jordan, and King Fahad Medical City in Riyadh, Saudi Arabia, between February 2014 and January 2015. Selected maternal characteristics and obstetric outcomes were compared between women who received prophylactic cervical cerclage and those who did not. Results: A total of 146 women with higher-order multiple pregnancies were included in the study; of these, 94 (64.4\%) underwent a prophylactic cervical cerclage insertion procedure and $52(35.6 \%)$ women did not. No significant difference was found between the two groups with regards to maternal age, parity or number of fetuses. However, the mean gestational age at delivery was significantly higher for women without compared to those with prophylactic cervical cerclage (32.9 weeks versus 31.7 weeks) according to both univariate and multivariate analyses $(P=0.013$ and 0.046 , respectively). Additionally, $40.4 \%$ of women without and $14.9 \%$ of women with prophylactic cervical cerclage gave birth after 34 gestational weeks $(P=0.003)$. Conclusion: Overall, prophylactic cervical cerclage was not associated with prolongation of the pregnancy among women with higherorder multiple pregnancies in the current study.

Keywords: Multiple Pregnancies; Preterm Births; Cervical Cerclage; Prophylactic Surgical Procedure; Jordan; Saudi Arabia.

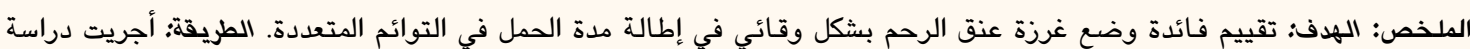

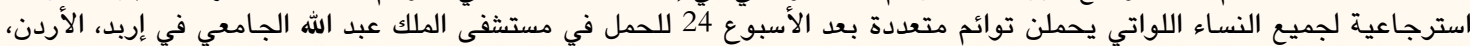

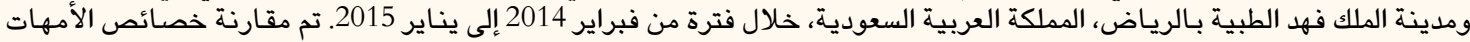

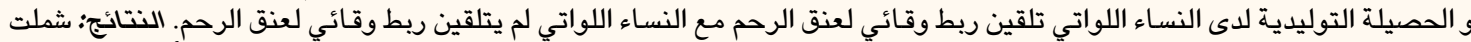

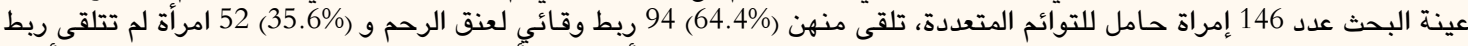

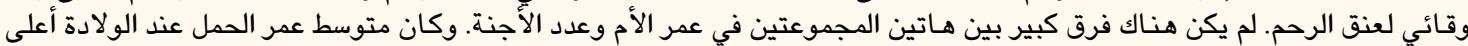

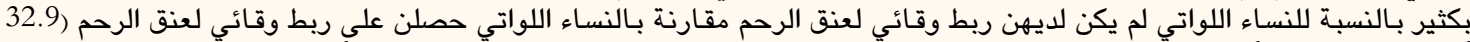

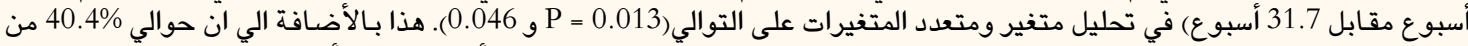

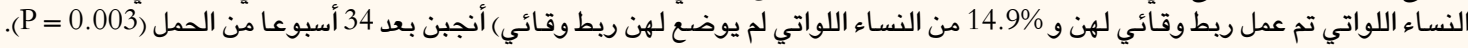
الخلاصة: لم يكن لريط عنق الرحم الوقائي فائدة لاطالة مدة الحمل في التوائم المت لمتعددة.

الكلمات المفتاحية؛ التوائم المتعددة؛ حمل التوائم؛ الولادة المبكرة؛ غرزة عنق الرحم؛ عنق الرحم؛ الأردن؛ المملكة العربية السعودية.

\section{AdVANCES IN KNOWLEDGE}

Preterm birth poses a great risk to the newborns of multiple pregnancies; however, reliable data are lacking concerning the effectiveness of prophylactic cervical cerclage in prolonging pregnancy.

This study confirmed that prophylactic cervical cerclage had no positive impact on perinatal outcomes among women with multiple pregnancies treated at institutions in Jordan and Saudi Arabia.

\section{Application to Patient Care}

Potential complications of prophylactic cervical cerclage placement include laceration, vaginal bleeding, infection, discharge, rupture of the fetal membranes and anaesthesia-related side-effects. The findings of this study do not support the use of this procedure among women with higher-order multiple pregnancies and may instead subject such patients to unnecessary and dangerous complications.

S NCE THE EARLY 1980S, THERE HAS BEEN AN alarming increase of over $400 \%$ in the incidence of higher-order multiple pregnancies due to the use of ovarian hyperstimulants by women after the birth of their first baby conceived via in vitro fertilisation. ${ }^{1-5}$ This increase has been associated with financial and logistical problems as well as higher perinatal morbidity and mortality rates among women 
with higher-order multiple pregnancies in comparison to their singleton counterparts. ${ }^{6-10}$ The rate of higherorder multiple pregnancies is especially high in certain countries, particularly those in the developing world where there are no legal restrictions on the number of embryos transferred at in vitro fertilisation centres. Despite advances in modern obstetric practice, preterm labour remains a difficult problem to prevent, stop or even delay in higher-order pregnancies. ${ }^{6-10}$

The approximate mean gestational age at delivery is $36,33,29$ and 28 weeks for twin, triplet, quadruplet and quintuplet pregnancies, respectively., ${ }^{5,811}$ While the pathophysiology of preterm birth in higher-order multiple pregnancies remains unclear, the most likely cause is overdistension of the uterus. ${ }^{12}$ Although routine prophylactic cervical cerclage has been suggested as a strategy for prolonging gestation and some evidence exists suggesting that its routine use in twin pregnancies is beneficial, its role or advantage in higher-order multiple pregnancies is unclear. ${ }^{8,9,13}$ This study therefore aimed to determine the effect of prophylactic cervical cerclage in the prolongation of higher-order multiple pregnancies.

\section{Methods}

All women with triplet or higher-order pregnancies beyond 24 gestational weeks seen between February 2014 and January 2015 at the King Abdullah University Hospital in Irbid, Jordan, or the King Fahad Medical City in Riyadh, Saudi Arabia, were included in this retrospective study. A review was conducted of the electronic patient databases at each tertiary institution. For maternal characteristics, the following variables were reviewed: age, parity and body mass index (BMI); history of previous cervical insufficiency, cervical surgery, preterm labour or premature rupture of membranes (PPROM); and number of fetuses and method of conception. Obstetric outcome measures included the incidence of preterm labour, PPROM and neonatal or intrauterine fetal death; admission to the neonatal intensive care unit (NICU); gestational age at delivery; and the mode and indications for delivery.

All patients were under the direct supervision of consultant obstetricians during their care. For women who received prophylactic cervical cerclage, the suture was placed into and around the cervix at between 11-16 gestational weeks, regardless of past obstetric history or the state of the cervix. All cerclage sutures were of the McDonald type, using $5 \mathrm{~mm}$ MERSILENE ${ }^{\circledR}$ polyester tape (Ethicon Inc., Somerville, New Jersey, USA), and were inserted under general anaesthesia with no specific instructions for suture placement. Following the procedure, patients received an ultrasound to check fetal wellbeing before being discharged on the same day, with instructions to seek attention at the emergency room if they experienced any symptomatic abnormalities. Patients were also advised to refrain from demanding physical activities but were not assigned complete bed rest. A follow-up visit to the antenatal clinic was arranged two weeks later to assess the state of the cervix. Patients were then seen regularly until the elective removal of the suture, or earlier in the case of an emergency. Most cervical cerclage sutures were removed during the $36^{\text {th }}$ gestational week without sedatives or any form of anaesthesia. No antimicrobial or tocolytic medications were administered. For patients in both groups, decisions regarding the timing and mode of delivery and pain relief options offered during labour were made according to the policies and protocols for higher-order multiple pregnancies at each institution.

The women were categorised into two groups for statistical analysis according to whether they had received prophylactic cervical cerclage or not. The sample size yielded a power of $>80 \%$ to detect a $5 \%$ difference in outcomes between the two groups. The Statistical Package for the Social Sciences (SPSS), Version 20.0 (IBM Corp., Armonk, New York, USA), was used to analyse the data. Chi-squared and Student's t-tests were used to compare percentages and means. A general linear model was used to conduct the regression analysis to determine statistical differences in gestational age at birth. The level of statistical significance was set at $P \leq 0.050$. This retrospective study received ethical approval from the institutional review boards at both the King Abdullah University Hospital and the King Fahad Medical City.

\section{Results}

A total of 146 women with higher-order multiple pregnancies were seen at the two tertiary institutions during the study period. Of these, 94 (64.4\%) underwent a prophylactic cervical cerclage insertion procedure and 52 (35.6\%) did not. The majority of the pregnancies (94.5\%) were the result of assisted reproductive techniques (ART), mainly intracytoplasmic sperm injection and embryo transfers; $98.9 \%$ of women with versus $86.5 \%$ of women without prophylactic cervical cerclage had used ART $(P=0.002)$. None of the women had a history of cervical insufficiency, prior cervical surgery, preterm labour or PPROM or had undergone fetal reduction. There was no statistically significant difference between the two groups in relation to maternal age $(P=0.674)$, parity $(P=0.177)$ 
Table 1: Maternal characteristics of women with higherorder multiple pregnancies treated at the King Abdullah University Hospital in Irbid, Jordan, and King Fahad Medical City in Riyadh, Saudi Arabia ( $\mathrm{N}=146)$

\begin{tabular}{|c|c|c|c|}
\hline \multirow[t]{2}{*}{ Characteristic } & \multicolumn{2}{|c|}{ n (\%) } & \multirow[t]{2}{*}{$P$ value } \\
\hline & $\begin{array}{c}\text { No PCC } \\
(n=52)\end{array}$ & $\begin{array}{c}\text { PCC } \\
(n=94)\end{array}$ & \\
\hline $\begin{array}{l}\text { Mean maternal age } \\
\text { in years } \pm S D\end{array}$ & $30.6 \pm 4.6$ & $30.9 \pm 5.1$ & 0.674 \\
\hline Nulliparity & $23(44.2)$ & $52(55.9)$ & 0.177 \\
\hline Number of fetuses & & & 0.563 \\
\hline $\begin{array}{l}\text { Quadruplets/ } \\
\text { quintuplets }\end{array}$ & $4(7.7)$ & $10(10.6)$ & \\
\hline Triplets & $48(92.3)$ & $84(89.4)$ & \\
\hline Use of ART & & & 0.002 \\
\hline No & $7(13.5)$ & $1(1.1)$ & \\
\hline Yes & $45(86.5)$ & 93 (98.9) & \\
\hline
\end{tabular}

or number of fetuses $(P=0.563)$ [Table 1]. In addition, no statistically significant differences were noted between the two groups with regards to BMI.

All of the women delivered by Caesarean section after 24 gestational weeks, with the majority of cases (92.5\%) considered emergency or urgent procedures. There was no statistically significant difference between the two groups in relation to the mode of delivery $(P=0.139)$, the occurrence of stillbirths or neonatal deaths $(P=0.406)$ or admission to the NICU $(P=0.682)$. However, $14.9 \%$ and $40.4 \%$ of women with and without prophylactic cervical cerclage, respectively, gave birth after 34 gestational weeks $(P=0.003)$. Moreover, the mean gestational age at delivery was significantly higher among women without compared to those with prophylactic cervical cerclage (32.9 versus 31.7 weeks; $P=0.013$ ) [Table 2]. This difference remained significant during the multivariate analysis after adjusting for ART, number of fetuses, parity and maternal age $(P=0.046)$.

Among those who received prophylactic cervical cerclage, there was no statistically significant difference in studied outcomes according to the time of cerclage insertion. The mean gestational age at delivery was 31.6 and 32.0 weeks for women who underwent the cerclage procedure at 11-13 and 14-16 gestational weeks, respectively $(P=0.542)$. One miscarriage occurred in the prophylactic cervical cerclage group. Of the women who had not initially received prophylactic cervical cerclage, none required subsequent emergency or rescue cerclage.
Table 2: Pregnancy outcomes among women with higher-order multiple pregnancies treated at the King Abdullah University Hospital in Irbid, Jordan, and King Fahad Medical City in Riyadh, Saudi Arabia ( $=146)$

\begin{tabular}{|c|c|c|c|}
\hline \multirow[t]{2}{*}{ Outcome } & \multicolumn{2}{|c|}{ n (\%) } & \multirow[t]{2}{*}{$P$ value } \\
\hline & $\begin{array}{c}\text { No PCC } \\
(\mathrm{n}=52)\end{array}$ & $\begin{array}{c}\text { PCC } \\
(n=94)\end{array}$ & \\
\hline \multicolumn{4}{|c|}{ Mode/indication of delivery } \\
\hline $\begin{array}{l}\text { Urgent CS due to } \\
\text { bleeding }\end{array}$ & $0(0.0)$ & $4(4.3)$ & 0.139 \\
\hline Elective CS & $6(11.5)$ & $5(5.3)$ & \\
\hline $\begin{array}{l}\text { Urgent CS due to } \\
\text { labour }\end{array}$ & $46(88.5)$ & $85(90.4)$ & \\
\hline \multicolumn{3}{|c|}{ Neonatal deaths/stillbirths } & 0.406 \\
\hline None & $46(88.5)$ & $87(92.6)$ & \\
\hline At least one & $6(11.5)$ & $7(7.4)$ & \\
\hline NICU admissions & & & 0.682 \\
\hline None & $3(5.8)$ & $4(4.3)$ & \\
\hline At least one & $49(94.2)$ & $90(95.7)$ & \\
\hline \multicolumn{3}{|c|}{ Gestational age at delivery in weeks } & 0.003 \\
\hline $24-31+6$ days & $19(36.5)$ & $50(53.2)$ & \\
\hline $32-34$ & $12(23.1)$ & $30(31.9)$ & \\
\hline$>34$ & $21(40.4)$ & $14(14.9)$ & \\
\hline Mean \pm SD & $32.9 \pm 2.7$ & $31.7 \pm 2.9$ & 0.013 \\
\hline
\end{tabular}

\section{Discussion}

Theoretically, there may be a higher pressure burden on the uterine cervix, particularly the internal opening of the cervix, in cases of higher-order multiple pregnancies in comparison to singleton pregnancies. ${ }^{12,13}$ Intuitively, a routine prophylactic cervical cerclage procedure for women with higher-order multiple pregnancies should automatically decrease the chances of preterm birth by preventing undue cervical shortening and dilatation. However, the role of the cervix in the aetiology of preterm birth in multiple pregnancies is not clear. Furthermore, the function of the cervix in higherorder multiple pregnancies might differ from that of singleton pregnancies. ${ }^{12,14}$ The anatomical status of the cervix and the likelihood of preterm birth can be evaluated by reviewing past obstetric history and carrying out a speculum or digital vaginal examination or reviewing abdominal and vaginal ultrasound findings in the second trimester. In comparison, the diagnosis of true cervical insufficiency is more challenging. ${ }^{15-17}$ 
The insertion of cervical cerclage sutures for patients with ultrasonographically-documented cervical shortening has been proposed so as to avoid unnecessary surgery. ${ }^{18}$ On the other hand, its effectiveness and safety in higher-order multiple pregnancy remains unclear. ${ }^{8,13,19}$ The criteria for patient and sample size selection and hospitalisation in previous research is not uniform..$^{10,19-21}$ Some studies have demonstrated that prophylactic cerclage is of no value in prolonging gestation in high-order multiple pregnancies..$^{10,14,19,22}$ In contrast, other studies have found that prophylactic cerclage significantly increases the mean gestational age and decreases the incidence of extreme prematurity. ${ }^{20-22}$ Nevertheless, routine prophylactic cervical cerclage is not recommended for every woman with a multiple pregnancy and the safety and efficacy of the procedure as a form of preterm birth prevention should be appraised on a case-by-case basis according to obstetric history and cervical assessment. ${ }^{12,14}$ In a study of current practices to prevent preterm births, Baker et al. found that the majority of Canadian specialists (82\%) recommended routine cervical length assessment at 16-21 gestational weeks, with none supporting routine cerclage insertion; however, $71 \%$ stated that they would perform cerclage based on the patient's history or an ultrasound. ${ }^{23}$

Prophylactic cerclage procedures in the current study were performed at between 11-16 gestational weeks, irrespective of obstetric history or cervical assessment. It is likely that this gestational age is somewhat early for cerclage, even in cases of multiple pregnancies in which there may yet be further physiological shortening of the uterine cervix. ${ }^{23}$ However, the timing of the prophylactic cervical cerclage insertion in the current study did not prolong pregnancy or have a significant difference on pregnancy outcomes. Limitations of the present study include its retrospective nature and the lack of randomisation in the selection of the patients. Furthermore, the incidence of immediate adverse effects of prophylactic cervical cerclage, such as rupture of the membranes, infection and pregnancy loss, between the date of the cerclage insertion and the beginning of the study when the women were at $\geq 24$ gestational weeks was not evaluated.

\section{Conclusion}

The current study found that the routine use of prophylactic cervical cerclage to prolong gestation among women with higher-order multiple pregnancies was not effective.

\section{CONFLICT OF INTEREST}

The authors declare no conflicts of interest.

\section{FUNDING}

No funding was received for this study.

\section{References}

1. Sumners JE, Moore ES, Ramsey CJ, Eggleston MK Transabdominal cervical cerclage in triplet pregnancies and risk of extreme prematurity and neonatal loss. J Obstet Gynaecol 2011; 31:111-17. doi: 10.3109/01443615.2010.542512.

2. Reddy UM, Wapner RJ, Rebar RW, Tasca RJ. Infertility, assisted reproductive technology, and adverse pregnancy outcomes: Executive summary of a National Institute of Child Health and Human Development workshop. Obstet Gynecol 2007; 109:967-77. doi: 10.1097/01.AOG.0000259316.04136.30.

3. Shinwell ES, Haklai T, Eventov-Friedman S. Outcome of multiplets. Neonatology 2009; 95:6-14. doi: 10.1159/000151750.

4. Wimalasundera RC, Trew G, Fisk NM. Reducing the incidence of twins and triplets. Best Pract Res Clin Obstet Gynaecol 2003; 17:309-29. doi: 10.1016/S1521-6934(02)00135-9.

5. Martin JA, Hamilton BE, Sutton PD, Ventura SJ, Menacker F, Kirmeyer S, et al. Births: Final data for 2005. Natl Vital Stat Rep 2007; 56:1-103.

6. Imaizumi Y. Infant mortality rates in single, twin and triplet births, and influencing factors in Japan, 1995-98. Paediatr Perinat Epidemiol 2001; 15:346-51. doi: 10.1046/j.1365-3016. 2001.00378.x.

7. Shinwell ES, Blickstein I, Lusky A, Reichman B. Excess risk of mortality in very low birthweight triplets: A national, population based study. Arch Dis Child Fetal Neonatal Ed 2003; 88:F36-40. doi: 10.1136/fn.88.1.F36.

8. Martin JA, Kung HC, Mathews TJ, Hoyert DL, Strobino DM, Guyer B, et al. Annual summary of vital statistics: 2006. Pediatrics 2008; 121:788-801. doi: 10.1542/peds.2007-3753.

9. Refuerzo JS, Momirova V, Peaceman AM, Sciscione A, Rouse DJ, Caritis $\mathrm{SN}$, et al. Neonatal outcomes in twin pregnancies delivered moderately preterm, late preterm, and term. Am J Perinatol 2010; 27:537-42. doi: 10.1055/s-0030-1248940.

10. Bernasko J, Lee R, Pagano M, Kohn N. Is routine prophylactic cervical cerclage associated with significant prolongation of triplet gestation? J Matern Fetal Neonatal Med 2006; 19:575-8. doi: $10.1080 / 14767050600825607$

11. Keith L, Oleszczuk JJ. Iatrogenic multiple birth, multiple pregnancy and assisted reproductive technologies. Int J Gynaecol Obstet 1999; 64:11-25. doi: 10.1016/S0020-7292 (98)00230-6.

12. Hodgson EJ, Lockwood CJ. Preterm birth: A complex disease. In: Berghella V, Ed. Preterm Birth: Prevention and management, 1st ed. Oxford, UK: Wiley-Blackwell, 2010. Pp. 8-16.

13. Rafael TJ, Berghella V, Alfirevic Z. Cervical stitch (cerclage) for preventing preterm birth in multiple pregnancy. Cochrane Database Syst Rev 2014; 9:CD009166. doi: 10.1002/14651858. CD009166.pub2.

14. Rebarber A, Roman AS, Istwan N, Rhea D, Stanziano G. Prophylactic cerclage in the management of triplet pregnancies. Am J Obstet Gynecol 2005; 193:1193-6. doi: 10.1016/j.ajog. 2005.05.076.

15. Rust OA, Atlas RO, Jones KJ, Benham BN, Balducci J. A randomized trial of cerclage versus no cerclage among patients with ultrasonographically detected second-trimester preterm dilatation of the internal os. Am J Obstet Gynecol 2000; 183:830-5. doi: 10.1067/mob.2000.109040 
16. Berghella V, Odibo AO, Tolosa JE. Cerclage for prevention of preterm birth in women with a short cervix found on transvaginal ultrasound examination: A randomized trial. Am J Obstet Gynecol 2004; 191:1311-17. doi: 10.1016/j.ajog. 2004.06.054.

17. To MS, Alfirevic Z, Heath VC, Cicero S, Cacho AM, Williamson PR, et al. Cervical cerclage for prevention of preterm delivery in women with short cervix: Randomised controlled trial. Lancet 2004; 363:1849-53. doi: 10.1016/S0140-6736(04)16351-4.

18. MRC/RCOG Working Party on Cervical Cerclage. Final report of the Medical Research Council/Royal College of Obstetricians and Gynaecologists multicentre randomised trial of cervical cerclage. Br J Obstet Gynaecol 1993; 100:516-23. doi: 10.1111/ j.1471-0528.1993.tb15300.x.

19. Mordel N, Zajicek G, Benshushan A, Schenker JG, Laufer N, Sadovsky E. Elective suture of uterine cervix in triplets. Am J Perinatol 1993; 10:14-16. doi: 10.1055/s-2007-994691.
20. Elimian A, Figueroa R, Nigam S, Verma U, Tejani N, Kirshenbaum N. Perinatal outcome of triplet gestation: Does prophylactic cerclage make a difference? J Matern Fetal Med 1999; 8:119-22. doi: 10.1002/(SICI)1520-6661(199905/06)8:3<119::AID-MFM9 $>3.0 . \mathrm{CO} ; 2-\mathrm{O}$.

21. Strauss A, Heer IM, Janssen U, Dannecker C, Hillemanns P, Müller-Egloff S. Routine cervical cerclage in higher order multiple gestation: Does it prolong the pregnancy? Twin Res 2002; 5:67-70. doi: 10.1375/1369052022910.

22. Goldman GA, Dicker D, Peleg D, Goldman JA. Is elective cerclage justified in the management of triplet and quadruplet pregnancy? Aust N Z J Obstet Gynaecol 1989; 29:9-12. doi: 10.1111/j.1479-828X.1989.tb02867.x.

23. Baker E, Hunter T, Okun N, Farine D. Current practices in the prediction and prevention of preterm birth in patients with higher-order multiple gestations. Am J Obstet Gynecol 2015; 212:671.e1-7. doi: 10.1016/j.jojog.2014.12.031. 